\title{
Desenvolvimento do Processo de Produção, Isolamento e Purificação de Pigmentos produzidos por Streptomyces carpaticus
}

\author{
F. B.D. PONTES ${ }^{1}$, J. F. B.PEREIRA1, A. BAPTISTA NETO ${ }^{1}$ \\ ${ }^{1}$ Universidade Estadual Paulista Júlio de Mesquita Filho, Departamento de Bioprocessos e \\ Biotecnologia \\ E-mail: feer.pontes@hotmail.com
}

\begin{abstract}
RESUMO - Atualmente a busca por novos compostos bioativos tem sido cada vez maior, a fim de obter substâncias que apresentem atividades antimicrobiana, anti-HIV, anti-tumoral, entre outras, desta forma, pesquisas em áreas e regiões ainda pouco exploradas são realizadas para que seja possível estudar e analisar microrganismos produtores de tais substâncias. As bactérias do gênero Streptomyces são importantes produtoras de diversos metabólitos secundários de grande interesse. Streptomyces carpaticus é uma bactéria de origem marinha capaz de produzir pigmentos com possível interesse industrial. Desta forma, o projeto objetivou avaliar o processo de extração de pigmentos produzidos em meio NBIMCC 185, utilizando sistema de duas fases aquosas (SAB) com líquidos iônicos (LI) para determinar o melhor sistema, sendo eles polipropilenoglicol/cloreto de colina $(\mathrm{PPG} /[\mathrm{Ch}] \mathrm{Cl})$ e fosfato tripotássico/cloreto de colina $\left(\mathrm{K}_{3} \mathrm{PO}_{4} /[\mathrm{Ch}] \mathrm{Cl}\right)$. Os resultados obtidos pelos parâmetros de separação, fator de purificação e rendimento de separação, indicaram melhores resultados para o segundo sistema, $\mathrm{K}_{3} \mathrm{PO}_{4} /[\mathrm{Ch}] \mathrm{Cl}$, sendo este adotado pata etapas futuras do projeto.
\end{abstract}

\section{INTRODUÇÃO}

A crescente necessidade em encontrar novos compostos bioativos que possuam atividades antimicrobiana, anti-HIV, anti-tumoral, entre outras, está propiciando grande aumento nas buscas por fontes alternativas para a obtenção destes compostos, para isto tem-se estudado, principalmente, microrganismos que até então são pouco explorados. Sabe-se que os microrganismos são excelentes produtores das mais variadas moléculas através de seu metabolismo primário ou secundário, as quais muitas vezes são dificilmente produzidas sinteticamente, sendo que a produção destas moléculas ocorre para as mais diversas finalidades. Cerca de $70 \%$ de todas as substâncias bioativas conhecidas são produzidas pelos Actinomicetos (Rachev et al, 2003), bactérias gram-positivas de importante papel na decomposição da matéria orgânica.

Visando por novas moléculas bioativas, tem-se intensificado a procura por novos locais que contenham microrganismos ainda pouco explorados, como exemplo o ambiente marinho. Estes microrganismos, que ocupam locais de temperaturas e pHs extremos, desenvolveram capacidades metabólicas únicas fornecendo grande potencial para produzir compostos não produzidos pelos microrganismos terrestres (Carvalho \& Fernandes, 2010), o que os torna 
altamente vantajosos. Com isso, novas pesquisas relacionadas ao Streptomyces carpaticus estão sendo feitas, microrganismo de origem marinha, que por ser do grupo das actinobactérias é importante fonte de metabólitos secundários, incluindo a valinomicina e de pigmentos de coloração escura em determinados meios de cultivo.

O estudo destes pigmentos torna-se importante, visto que cada vez mais pesquisas são realizadas para obter novas fontes de corantes e pigmentos naturais. Essas pesquisas são motivadas pelo fato de alguns destes compostos, além de apresentarem a função de fornecerem cor a diversos alimentos e serem substitutos aos compostos de via sintética, podem apresentar inúmeros benefícios à saúde humana (Rodriguez-Amaya, 2016). Diversos microrganismos do grupo dos actinomicetos são reconhecidos pela biossíntese de melanina ou pigmentos melanóides, os quais são polímeros de estrutura molecular diversa de coloração escura, geralmente marrom ou preta, com a função relacionada à sobrevivência da espécie em condições adversas (Almeida-Paes et al, 2012). Estes pigmentos podem ser produzidos tanto em meios proteicos, como também em meios sintéticos quando há a presença nitrogênio $(\mathrm{N})$ inorgânico. Quando a melanina é sintetizada em meios proteicos, as enzimas fenoloxidase e tirosinase transformam L-tirosina em L-DOPA e este em DOPAcromp, o qual é autooxidado a indol-5,6-quinona, e posteriormente, de maneira espontânea, em DOPA-melanina (Petinate et al, 1999).

Sendo assim o isolamento, a caracterização e a avaliação do processo de produção são importantes para determinar a viabilidade de produção ou não de novos pigmentos que podem trazer benefícios a sociedade, posto que este possa ser uma nova vertente nas indústrias alimentícias e até mesmo farmacêuticas, sendo assim o objetivo deste trabalho é mostrar os resultados preliminares dos estudos da extração do pigmento utilizando duas fases aquosas Em estudos anteriores, observou que estes pigmentos são substâncias de baixa solubilidade em solventes polares e praticamente insolúvel em solventes apolares. Devido as possíveis aplicações dos pigmentos, realizou-se, neste trabalho, a extração destes utilizando líquido iônico que devido suas propriedades físicas variáveis, baixo ponto de fusão, boa estabilidade térmica, não agressão ao ambiente e propriedades favoráveis de solvatação para moléculas polares ou apolares (Lee \& Row, 2016) permitem seu uso na extração destes pigmentos. Considerando-se o exposto, o presente projeto tem por finalidade avaliar o processo de separação do pigmento produzido pelo microrganismo através de sistema de extração de duas fases líquidas utilizando um sistema de líquido iônico.

\section{METODOLOGIA}

\subsection{Microrganismo}

Utilizou-se Streptomyces carpaticus isolado a partir de sedimentos marinhos em São Sebastião-SP, armazenados em criotubos de $3 \mathrm{~mL}$ contendo solução de glicerol $20 \%$ a $-80^{\circ} \mathrm{C}$.

\subsection{Meios De Cultivo}

Utilizaram-se os meios GYM (extrato de levedura $(4,0 \mathrm{~g} / \mathrm{L})$; glicose $(4,0 \mathrm{~g} / \mathrm{L})$; extrato de malte $(10,0 \mathrm{~g} / \mathrm{L})$; CaCO3 $(1,0 \mathrm{~g} / \mathrm{L}), \mathrm{pH} 7,0)$ para reativação e meio NBIMCC $185(\mathrm{~g} / \mathrm{L})$ (glicose $(10,0)$; extrato de levedura $(1,0)$; extrato de carne $(4,0) ; \mathrm{NaCl}(2,5)$, peptona $(4,0), \mathrm{pH}$ $7,2)$ para meio de produção. 


\subsection{Cultivos Em Mesa Incubadora Rotativa}

$\mathrm{Na}$ etapa de reativação, $3,5 \mathrm{~mL}$ de suspensão de células vegetativas de bactérias contidas nos criotubos foram inoculadas em frascos Erlenmeyers de $500 \mathrm{~mL}$ contendo $50 \mathrm{~mL}$ de meio GYM e incubados por $24 \mathrm{~h}$. Na etapa de produção, $5 \mathrm{~mL}$ da suspensão anterior foram adicionados a Erlenmeyers de $500 \mathrm{~mL}$ contendo $45 \mathrm{~mL}$ de meio de produção e incubados por 120h. O cultivo foi realizado a $28^{\circ} \mathrm{C}$, controlado pelo "shaker" agitado orbitalmente a 250rpm. Ao final do cultivo, o caldo passou por etapa de centrifugação (11.000rpm, 15 minutos, $25^{\circ} \mathrm{C}$ ) para posterior análise das amostras quanto à produção de pigmentos.

\subsection{Separação E Purificação Dos Pigmentos}

A fim de determinar os picos de maior absorção referentes ao pigmento fez-se a varredura das amostras com diluições conhecidas em espectrofotômetro UV-Vis. Utilizou-se água destilada como branco para leitura em espectrofotômetro.

A separação e purificação dos pigmentos ocorreram utilizando sistemas de separação de duas fases aquosas com líquidos iônicos. Dois diferentes sistemas de separação foram analisados, sendo eles, Sistema 1 (PPG 400/[Ch]Cl, 30\% PPG 400, 20\% [Ch]Cl, 10\% do caldo fermentado e $40 \%$ água) e Sistema $2\left(\mathrm{~K}_{3} \mathrm{PO}_{4} /[\mathrm{Ch}] \mathrm{Cl}, 30 \% \mathrm{~K}_{3} \mathrm{PO}_{4}, 20 \%\right.$ [Ch]Cl, $10 \%$ do caldo fermentado e $40 \%$ água). Após homogeneização dos sistemas, os mesmos foram mantidos em repouso por 24 horas. As fases dos sistemas foram separadas, tendo seus volumes anotados e em seguida, a fase fundo para o Sistema 1 e a fase topo para o Sistema 2, onde foi identificado visualmente maior concentração de pigmentos, tiveram suas absorbâncias medidas nos comprimentos de onda determinados na varredura. Para leitura em espectrofotômetro, fez-se branco para cada um dos sistemas substituindo o caldo fermentado por água. Após leitura das absorbâncias, realizou-se o cálculo do fator de purificação e rendimento da separação para determinar qual o sistema melhor adequou-se para separação do pigmento. Fator de purificação $(\mathrm{PF})$ e rendimento $(\boldsymbol{\eta})$ para o Sistema 1 e Fator de purificação $(\mathrm{PF})$ e rendimento $(\boldsymbol{\eta})$ para Sistema 2 foram determinados pelas Equações 1 e 2.

$$
\begin{gathered}
F P=\frac{\left(\frac{A b s(x) n m}{A b s 298 n m}\right)_{F R P}}{\left(\frac{A b s(x) n m}{A b s 298 n m}\right)_{A B}} \\
\eta=\frac{\left(A b s(x)_{F R P} * V_{F R P}\right)}{\left(A b s(x)_{A B} * V_{A B}\right)}
\end{gathered}
$$

Onde: $\mathrm{ABS}(\mathrm{x}) \mathrm{nm}$ indica absorbância em comprimento de onda determinado experimentalmente, ABS 298nm é a medida de absorbância lida a $298 \mathrm{~nm}$, V indica volume das fases. $O$ subscrito FRP significa da fase rica em pigmento e o subscrito AB da amostra bruta. 


\section{RESULTADOS}

\subsection{Produção De Pigmentos Escuros}

Conforme descrito na literatura o grupo dos actinomicetos tem a capacidade de produzir e excretar pigmentos escuros na presença de alguns componentes do meio de cultivo. No caso deste trabalho, a produção de pigmentos pode ser associada à transformação de aminoácidos aromáticos, que estão presentes em grandes quantidades nos componentes deste meio, sendo assim, a utilização do meio NBIMCC 185 para esta finalidade mostra-se satisfatória, como observado na Figura 1. Resultado semelhante foi encontrado no trabalho de Petinate et al (1999) em que a produção de pigmentos escuros utilizando Streptomyces cyaneus foi identificada.

Figura 1- Produção de pigmentos escuros por Streptomyces carpaticus. Da esquerda para a direita, caldo de cultivo NBIMCC 185 no momento de inoculação e caldo de cultivo após $120 \mathrm{~h}$ em mesa incubadora rotativa a $28^{\circ} \mathrm{C} / 250 \mathrm{rpm}$.

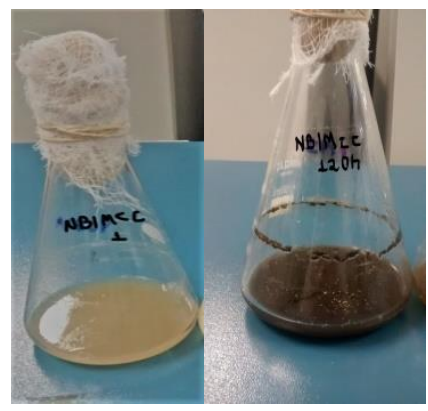

\subsection{Separação e purificação dos pigmentos}

A partir da análise visual dos sistemas de separação, identifica-se que o Sistema 2 $(\mathrm{K} 3 \mathrm{PO} 4 /[\mathrm{Ch}] \mathrm{Cl})$ mostrou- se mais eficiente na partição dos pigmentos para uma das fases. No Sistema 1 percebeu-se turbidez, além de visualmente apresentar presença dos pigmentos escuros em ambas as fases. Desta forma, estudos futuros serão conduzidos adotando o segundo sistema. A Figura 2 demonstra a partição dos pigmentos entre as fases para ambos os sistemas.

Figura 2- Separação dos pigmentos em SAB utilizando líquidos iônicos (à esquerda Sistema 1 e à direita Sistema 2).

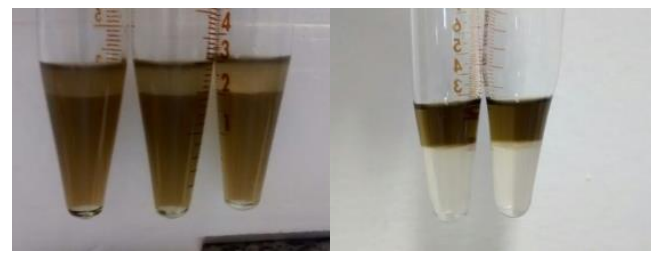


$\mathrm{Na}$ análise de varredura em espectrofotômetro foram identificados dois diferentes comprimentos de onda onde a absorbância era maior, sendo eles $298 \mathrm{~nm}$ e $448 \mathrm{~nm}$, porém cadeias laterais de aminoácidos selecionados, como tirosina e triptofano, absorvem em UV a $280 \mathrm{~nm}$, desta forma por ter sido utilizado o caldo fermentando contendo o pigmento e outros componentes de base proteica justifica-se que neste comprimento de onda a absorbância tenha sido a máxima observada. Sendo assim, a absorbância no comprimento de onda em $280 \mathrm{~nm}$ foi considerada como medida indireta da concentração de proteínas com aminoácidos aromáticos e os valores utilizados para o cálculo dos valores de FP. Conhecendo-se os volumes das fases topo e fundo, volume final e as absorbâncias determinadas foi possível determinar os parâmetros fator de purificação e rendimento que constam na Tabela 1 .

Tabela 1- Fatores de purificação e rendimento de separação nos sistemas de duas fases aquosas para separação dos pigmentos.

\begin{tabular}{lcl}
\hline & Sistema 1 & Sistema 2 \\
\hline FP 1 & $448 \mathrm{~nm}$ & $448 \mathrm{~nm}$ \\
FP 2 & 1,14641 & 0,92818 \\
FP 3 & 1,25256 & 0,96505 \\
$\boldsymbol{\eta}$ 1 (\%) & 1,1272 & - \\
$\boldsymbol{\eta}$ 2 (\%) & 86,3363 & 99,201 \\
$\boldsymbol{\eta}$ 3 (\%) & 88,3634 & 98,94 \\
\hline
\end{tabular}

Para o Sistema 1, através da análise de condutividades nas fases topo e fundo determinouse a fase topo rica em PPG 400 e a fase fundo rica em $[\mathrm{Ch}] \mathrm{Cl}$, sendo assim o pigmento, nestas condições apresentou maior afinidade pela fase rica em LI.

Os valores de FP refletem o quanto foi possível purificar um produto em relação à amostra bruta e os valores de rendimento refletem o quanto se consegue recuperar após a realização do processo. Observa-se um alto rendimento de processo, porém com baixa capacidade de purificação (refletido em valores próximos a 1 de FP). Isso nos leva as seguintes hipóteses: i) o sistema de extração não está sendo eficiente, sendo necessário alterar ou o líquido iônico ou o polímero ou sal no processo de extração e ii) a metodologia de medida de contaminantes não está adequada.

A separação de um determinado composto entre duas fases em um sistema SAB é complexa e ocorre por diversas interações entre o composto a ser particionado e os cmponentes que formam as fases. O pigmento a ser separado e as demais proteínas presentes no meio podem interagir através de ligações de hidrogênio, forças dispersivas ou interações eletrostáticas (Taha et al, 2015). Desta forma, considerando-se os fatores de purificação para ambos os sistemas, percebe-se que apesar do pigmento migrar majoritariamente para a fase contendo LI, não foi possível que houvesse boa separação de outras proteínas e dos demais contaminantes. Propõe-se como futuras alternativas avaliar as proteínas totais do sistema através de outros métodos a fim de se reduzir possíveis erros. 


\section{CONCLUSÃO}

Os pigmentos produzidos pelo Streptomyces carpaticus ainda são pouco estudados, desta forma, este trabalho auxilia na caracterização dos mesmos, indicando que estes pigmentos apresentam boa afinidade ao cloreto de colina. Sendo assim, é possível conduzir trabalhos futuros de purificação destes pigmentos utilizando o Sistema 2 aqui adotado, o qual apresentou bons rendimentos de extração. Além disso, este trabalho torna-se importante por demonstrar a capacidade do microrganismo estudado em produzir pigmentos escuros com possível aplicação em variadas áreas, assim como outros microrganismos de seu grupo.

\section{REFERÊNCIAS BIBLIOGRÁFICAS}

ALMEIDA-PAES, Rodrigo et al. Biosynthesis and functions of a melanoid pigment produced by species of the Sporothrix complex in the presence of L-tyrosine. Applied and environmental microbiology, v. 78, n. 24, p. 8623-8630, 2012.

CARVALHO, C. C. C. R. de, FERNANDES, P. Production of metabolites as bacterial responses to the marine enviroment. Marine Drugs, v.8, p. 705-727, 2010.

LEE, Yu Ri; ROW, Kyung Ho. Comparison of ionic liquids and deep eutectic solvents as additives for the ultrasonic extraction of astaxanthin from marine plants. Journal of Industrial and Engineering Chemistry, 2016.

PETINATE, S. D., MARTINS, R. M., COELHO, R. R., MEIRELlES, M. N. L., BRANQUINHA, M. H., \& VERMELHO, A. B. Influence of growth medium in proteinase and pigment production by Streptomyces cyaneus. Memórias do Instituto Oswaldo Cruz, 94(2), 173-177, 1999.

RACHEV, R., GESHEVA, V., TEWFIKE, T., BOJKOVA, S., \& ZVETKOVA, R. A new antibiotic, TH818, and its properties. Biotechnology and applied biochemistry, 37(1), 21-26, 2003.

RODRIGUEZ-AMAYA, D. B. Natural food pigments and colorants. Current Opinion in Food Science, 7, 20-26. 2016

TAHA, M., QUENTAL, M. V., CORREIA, I., FREIRE, M. G., \& COUTINHO, J. A. (2015). Extraction and stability of bovine serum albumin (BSA) using cholinium-based Good's buffers ionic liquids. Process Biochemistry, 50(7), 1158-1166. 